This is the final peer-reviewed accepted manuscript of

Pignotti, Emanuela; Casas, Gemma; Llorca, Marta; Tellbüscher, Anil; Almeida, David; Dinelli, Enrico; Farré, Marinella; Barceló, Damià: Seasonal variations in the occurrence of perfluoroalkyl substances in water, sediment and fish samples from Ebro Delta (Catalonia, Spain). SCIENCE OF THE TOTAL ENVIRONMENT, 607608. ISSN 0048-9697

DOI: $10.1016 /$ j.scitotenv.2017.07.025

The final published version is available online at:

http://dx.doi.org/10.1016/j.scitotenv.2017.07.025

Rights / License:

The terms and conditions for the reuse of this version of the manuscript are specified in the publishing policy. For all terms of use and more information see the publisher's website.

This item was downloaded from IRIS Università di Bologna (https://cris.unibo.it/)

When citing, please refer to the published version. 


\title{
Seasonal variations in the occurrence of perfluoroalkyl substances in water, sediment and fish samples from Ebro Delta (Catalonia, Spain)
}

\author{
Emanuela Pignotti $^{\text {a,b }}$, Gemma Casas ${ }^{\text {b }}$, Marta Llorca ${ }^{\text {b }}$, Anil Tellbüscher ${ }^{\text {b,c }}$, David Almeida ${ }^{\text {d }}$, Enrico Dinelli ${ }^{a}$, \\ Marinella Farré ${ }^{\mathrm{b}, *}$, Damià Barceló ${ }^{\mathrm{b}, \mathrm{e}}$ \\ ${ }^{a}$ Department of Biological, Geological and Environmental Sciences, Bologna University - Branch Office Ravenna, Sant'Alberto, 163, 48123 Ravenna, Italy \\ b Water and Soil Quality Research Group, Department of Environmental Chemistry, IDAEA-CSIC, Jordi Girona 18-26, 08034 Barcelona, Spain \\ c Department of Chemistry, University Duisburg-Essen, Germany \\ d GRECO, Institute of Aquatic Ecology, University of Girona, 17003 Girona, Spain \\ ${ }^{\text {e } C a t a l a n}$ Institute for Water Research (ICRA), H2O Building, Scientific and Technological Park of the University of Girona, Emili Grahit 101, 17003 Girona, Spain
}

\section{H I G H L I G H T S}

- Seasonal variations of perfluoroalkyl substances in the Ebro Delta Area were studied.

- PFOA was the most frequently detected in water and sediments.

- Levels of PFASs in waters were characterised by a slight decrease during winter.

- Levels of PFASs in sediments showed a progressive decrease from autumn to summer.
GRAPH ICA L A B S T R A C T



A B S T R A C T

The main objective of this study was to assess the concentration levels and the seasonal variations of 13 poly and perfluoroalkyl substances (PFASs) in different compartments (water, sediments and fish) of the Ebro Delta (NE Spain) and surrounding coastal areas. Perfluorooctanoic acid (PFOA) was the most frequently detected compound in waters and sediments. Perfluorocarboxylic acids (PFCAs) were the compounds found at the highest concentra tions in water samples. On the other hand, sediments were more enriched in perfluorooctanesulfonate (PFOS) (range $<1.0222 .6 \mathrm{ng} / \mathrm{g} \mathrm{dw}$ ). Waters and sediments showed a different seasonal trend. While waters were characterised by a substantial constant level of PFASs over the year, sediments showed a progressive decrease from autumn to summer, revealing the great influence that environmental conditions exert on PFAS distribution in sediments. As regards fish samples, in spite of the ban of its production, PFOS was the most frequently detected compound in seawater fishes, in agreement with its high persistency, bioaccumulation and biomagnification. More over, PFASs showed to be more distributed in the skin rather than in muscle tissues. In addition, river fishes were characterised by very high PFAS levels ( $\sum$ PFAS range from $63.8 \mathrm{ng} / \mathrm{g}$ ww to $938 \mathrm{ng} / \mathrm{g} \mathrm{ww}$ ), with perfluoroalkyl carboxylic acids being more concentrated than sulfonates. The PFASs concentrations in water, sediment, and biota revealed that one of the studied sites, Isla de Buda was the most contaminated site of the Ebro Delta. These results are consistent with its location at the final part of the estuary, where many irrigation channels are collected together.

\footnotetext{
* Corresponding author.

E-mail address: mfuqam@cid.csic.es (M. Farré).
} 


\section{Introduction}

Poly and perfluoroalkyl substances (PFASs) are a wide group of synthetic substances with multiple industrial and domestic applications, such as stain repellents coatings for textiles and fire fighting foams among many others (Arvaniti and Stasinakis, 2015; Zareitalabad et al., 2013). Because of the strong carbon fluorine bond, these compounds are characterised by high thermal, chemical and biological stability. However, due to this high stability, they have been found to be persistent in the environment, with compounds such as the perfluorooctanesulfonate (PFOS) having a half life of more than two months in waters and over six months in soils and sediments (Renzi et al., 2013). Moreover, PFASs show a tendency to bioaccumulate and biomagnify through the food chain (Ahrens et al., 2011; Naile et al., 2010), potentially causing adverse effects on organisms, such as hepato toxicity reduction of the immune function among others (Lau et al., 2007; Zhang et al., 2013). Therefore, due to their persistence, accumula tion in living organisms, the toxicity of some compounds and their wide distribution in the environment, the occurrence of PFASs is a cause for concern, and nowadays they are considered as emerging organic con taminants. For these reasons, the European Commission (EC) has set PFOS and its derivatives in the list of priority hazardous substances and has identified water and fish threshold concentrations for environ mental quality assessment under the Water Framework Directive (WFD) (WFD, 2012). However, there is still a lack of legislation concerning most of these compounds in drinking water and food. More over, the Directive 2013/39/EC (EU Commission, 2013) laid down envi ronmental quality standards (EQS) for priority substances in water and biota. The EQSs set for PFOS are $0.65 \mathrm{ng} / \mathrm{l}$ in inland surface waters (annu al average concentration), 36 $\mu \mathrm{g} / \mathrm{l}$ as maximum allowable concentration, and $9.1 \mu \mathrm{g} / \mathrm{kg}$ in biota. In the US Environmental Protection Agency (US EPA, 2016) has proposed a provisional threshold (between 0.01 and $0.09 \mu \mathrm{g} / \mathrm{l}$ ) for drinking water with respect to only 7 compounds, includ ing PFOS and perfluorooctanoic acid (PFOA).

Manufacturing facilities are considered to be one of the main sources of contamination by PFASs (Prevedouros et al., 2006; Pistocchi and Loos, 2009), along with wastewater treatment plants (WWTPs), which have been found to be inefficient in the removal of these compounds from wastewater influents (Ahrens et al., 2009; Boulanger et al., 2005; Schultz et al., 2006). Once released into the aquatic environment, they can easily be transferred into different environmental compartments, reaching groundwater (Houtz et al., 2013), soils (Houtz et al., 2013), sediments (Gao et al., 2015) and biota (Campo et al., 2016). Further more, these compounds have been found in remote environments, such as the Antarctica region (Llorca et al., 2012a). Once in the aquatic environment, PFASs are accumulated and biomagnified through the aquatic food chain whereby they reach human food (Pérez et al., 2014) and drinking water (Llorca et al., 2012b; Schwanz et al., 2016). The partitioning mechanism and their fate in the environment, though, are still not well known (Ahrens, 2011). In addition, most studies have been mainly focused on more persistent and accumulative compounds such as PFOS and PFOA, while less information has been reported regarding the use of short chain PFAS in the substitution of the 8 carbon chain compounds.

Different studies have already investigated the occurrence of PFASs in the aquatic environment, mainly focusing on their distribution in fresh waters, particularly rivers (Ahrens, 2011; Loos et al., 2013a; Munoz et al., 2015; Valsecchi et al., 2015; Lorenzo et al., 2016). But, up until now, scarce information is available about their seasonal fluctua tion in coastal and highly productive areas, such as estuarine habitats. Those are fragile ecosystems that can be highly affected by human activ ities since they receive urban sewages and other by products of human activities (Jiang et al., 2014).

Within this context, the main aim of this study was to assess the occurrence and environmental fate of 13 PFASs in the Ebro Delta (NE of Spain), as well as the surrounding coast: 8 perfluorocarboxylic acids, 4 perfluorosulfonates and 1 sulfonamide in a total number of 213 samples (87 waters, 71 sediments and 55 fishes). These compounds were analysed in the water, sediment and fish samples during three different seasons.

\section{Materials and methods}

\subsection{Chemicals and reagents}

Perfluoroalkyl compounds standards were provided by Wellington Laboratories Inc. (Canada) and were composed of: (i) a mixture of PFASs (PFAC MXB, $2 \mu \mathrm{g} / \mathrm{ml}$ in methanol, purity $>98 \%$ ) containing perfluoropentanoic (PFPeA), perfluorohexanoic (PFHxA), perfluoroheptanoic (PFHpA), perfluorooctanoic (PFOA), perfluorononanoic (PFNA), perfluorodecanoic (PFDA), perfluoroundecanoic (PFUdA) and perfluorododecanoic (PFDoA) acids, and perfluorobutanesulfonate (PFBS), perfluorohexanesulfonate (PFHxS), perfluorooctanesulfonate (PFOS), perfluorodecane sulfonate (PFDS); and (ii) the perfluoroctanesulfonamide (PFOSA). Surrogate in ternal standards used for quantification normalisation were supplied by Wellington Laboratories Inc. (Canada), and included: (i) a mixture of labelled PFASs (MPFAC MXA, $2 \mu \mathrm{g} / \mathrm{ml}$ in methanol, purity $>98 \%$ ), composed of ${ }^{18} \mathrm{O}_{2}$ perfluorohexanesulfonate (MPFHxS 1802), ${ }^{13} \mathrm{C}_{2}$ perfluorohexanoic acid (MPFHxA $13 \mathrm{C} 2$ ), ${ }^{13} \mathrm{C}_{4}$ perlfuorooctanesulfonate (MPFOS $13 \mathrm{C} 4$ ), ${ }^{13} \mathrm{C}_{4}$ perfluorooctanoic acid (MPFOA 13C4), ${ }^{13} \mathrm{C}_{5}$ perfluorononanoic acid (MPFNA $13 \mathrm{C} 5$ ), ${ }^{13} \mathrm{C}_{2}$ perfluorodecanoic acid (MPFDA $13 \mathrm{C} 2$ ), ${ }^{13} \mathrm{C}_{2}$ perfluorododecanoic acid (MPFDoA 13C2); and (ii) ${ }^{13} \mathrm{C}_{8}$ perfluorooctanesulfonamide (M8FOSA, $>99 \%$ ).

All solvents and reagents were of analytical grade. Water and methanol (CHROMASOLV® Plus), ammonium acetate (MW: 77.08, purity $>98 \%$ ), and ammonium hydroxide (MW: 35.05 , purity $>98 \%$ ) were purchased from Sigma Aldrich (Steinheim, Germany).

\subsection{Area of study}

The Ebro Delta is the third largest delta in the Mediterranean Sea. It is a wetland area of $320 \mathrm{~km}^{2}$, highly relevant for conservation, which is included in the Ramsar Convention list. This estuarine habitat is characterised by a high biological productivity, thanks to the nutrients that are provided by the Ebro River (Lloret et al., 2004). The climate in the middle and lowland reaches of the River Ebro is typically Mediterra nean, with rainfall concentrated in autumn and spring (200 $300 \mathrm{~mm})$ and intense summer drought $(<50 \mathrm{~mm})$. Flow regime is pluvio nival because of the left margin tributaries from the Pyrenees. The average annual temperature is between 10 and $15^{\circ} \mathrm{C}$. The lowest temperatures occur in winter (down to $-5{ }^{\circ} \mathrm{C}$ ) and the highest in summer $\left(>40{ }^{\circ} \mathrm{C}\right)$. Substratum in the area is mainly calcareous, with Cenozoic limestones, gypsum and alluvial sediments. Aquatic vegetation consists of macro phytes such as water crowfoot Ranunculus spp. and Scirpus spp. The land use is mainly for agriculture and cattle rearing approximately $13 \%$ of its total surface is composed of natural lagoons, bays and marshes, whereas the major part (77\%) is dedicated mainly to agricul tural activity such as rice and orchards. For this reason, since the 1960s, different dams and irrigation channels have been built in order to control Ebro River water and sediment inputs and to fulfil the sur rounding water demand (Cardoch et al., 2002).

Amposta, Deltebre, Sant Jaume d'Enveja and Sant Carles de la Ràpita are the main towns that are located in this area, and they can potentially affect estuary environmental quality with the discharge of their treated sewages into the Ebro River. Chemical industries and a nuclear power plant on the northern side of the area (province of Tarragona) may be additional sources of contamination. 


\subsection{Sampling}

Three sampling campaigns were carried out during October November 2015 (autumn), February April 2016 (winter), and June July 2016 (spring summer). A total number of 213 samples including 87 water, 71 sediment and 55 fish samples were collected. During the first campaign (i.e. autumn), only water and sediment were sampled, while fish samples were collected in the second (i.e. winter) and third (i.e. spring summer) sampling campaigns, in addition to water and sediment. Detailed information about the locations of sampling sites and the samples are listed in Table S1 from Supporting information. In summary, water samples were collected from the Ebro River at 7 irrigation channels, from the emissary of the wastewater treatments plant (WWTP) that is located in Sant Carles de la Ràpita, at the influents and the effluents of 2 WWTPs (Sant Carles de la Rapita and Amposta); estu ary water samples were collected in different lagoons (Illa de Buda, L'Encanyissada, La Tancada and Canal Vell) and seawater samples from the Fangar and Alfacs bays and at the open sea adjacent to these bays. Fish samples were collected both from seawater (during winter season) and from freshwater (during spring summer period). Detailed information about fish communities is shown in Table 1. Regarding sea water fishes, a total of 15 specimens of different species were sampled from two sites of the Mediterranean Sea (Fangar bay, $\mathrm{n}$ $=4$; Alfacs Bay, $\mathrm{n}=5$ ) and from one Ebro Delta site (Illa de Buda lagoon, $\mathrm{n}=6$ ). In particular, fish species were Mugil cephalus, Squalius laietanus, Cyprinus carpio, Anguilla anguilla, Torpedo torpedo, Sarpa salpa, Trachurus mediterraneus, Boops boops, Diplodus annularis and Micropterus salmoides. Fish were sampled by local fishers using nets. Individual fish samples were measured for fork/total length (FL/TL, \pm 1 $\mathrm{mm}$ ), weighed (wet body weight, $\pm 0.1 \mathrm{~g}$ ), labelled, stored in ice and frozen $\left(-20^{\circ} \mathrm{C}\right)$ on the same date of collection.

Riverine fishes $(n=40)$ sampled during the spring summer period were collected from two sites of the Ebro River upstream of the Delta: Xerta $(\mathrm{n}=21)$ and Tortosa $(\mathrm{n}=19)$. In particular, fish species were Alburnus alburnus, Cyprinus carpio, Liza sp., Rutilus rutilus, Scardinius erythrophtalmus, Silurus glanis, and Squalius laietanus. To encompass the existing environmental variability, fish were collected from all meso habitats present in the river (e.g. runs, riffles and pools), from the left and right margins along each sampling site (500 m river length). This allowed collecting a representative sample of fishes. Fishes were sampled by electrofishing from a boat $(4.5 \mathrm{~m}$ aluminium hull) by using a 2000 W DC generator at $1000 \mathrm{~V}$ and 16 A (Model: 5.0 GPP

\section{Table 1}

Fish communities.

\begin{tabular}{|c|c|c|c|c|}
\hline Habitat & Scientific name & Common name & $\begin{array}{l}\text { Taxonomic } \\
\text { family }\end{array}$ & Origin \\
\hline Sea & Torpedo torpedo & $\begin{array}{l}\text { Common } \\
\text { torpedo }\end{array}$ & Torpedinidae & Native \\
\hline Sea & $\begin{array}{l}\text { Trachurus } \\
\text { mediterraneus }\end{array}$ & Jack mackerel & Carangidae & Native \\
\hline Sea & Boops boops & Bogue & Sparidae & Native \\
\hline Sea & Diplodus annularis & $\begin{array}{l}\text { Annular sea } \\
\text { bream }\end{array}$ & Sparidae & Native \\
\hline Sea & Sarpa salpa & Salema & Sparidae & Native \\
\hline Delta & Anguilla anguilla & European eel & Anguillidae & Native \\
\hline Delta & $\begin{array}{l}\text { Micropterus } \\
\text { salmoides }\end{array}$ & $\begin{array}{l}\text { Largemouth } \\
\text { bass }\end{array}$ & Centrarchidae & Non-native \\
\hline Delta & Mugil cephalus & $\begin{array}{l}\text { Flathead grey } \\
\text { mullet }\end{array}$ & Mugilidae & Native \\
\hline Delta/river & Squalius laietanus & Ebro chub & Cyprinidae & Native \\
\hline Delta/river & Cyprinus carpio & Common carp & Cyprinidae & Non-native \\
\hline River & Alburnus alburnus & Bleak & Cyprinidae & Non-native \\
\hline River & Rutilus rutilus & Roach & Cyprinidae & Non-native \\
\hline River & $\begin{array}{l}\text { Scardinius } \\
\text { erythrophtalmus }\end{array}$ & Rudd & Cyprinidae & Non-native \\
\hline River & Silurus glanis & $\begin{array}{l}\text { European } \\
\text { catfish }\end{array}$ & Siluridae & Non-native \\
\hline River & Liza sp. & Mullet sp. & Mugilidae & Native \\
\hline
\end{tabular}

Smith Root Inc., Vancouver, WA, USA), along with dip nets (2.5 m long pole, $50 \mathrm{~cm}$ diameter net, $10 \mathrm{~mm}$ mesh size). Two anodes were suspended from booms and mounted on the bow of the boat, and a cathode was mounted along each side of the hull. A single pass was made following a zigzagging and upstream direction without using block nets in every sampling site. After each survey was concluded, fish were identified until the species level and counted. Then, a fish sub sample was immediately immersed in an overdose solution of an aesthetic (MS 222) for $15 \mathrm{~min}$. Euthanized fish were measured for fork/total length (FL/TL, $\pm 1 \mathrm{~mm}$ ), weighed (wet body weight, $\pm 0.1 \mathrm{~g}$ ), labelled, stored in ice and frozen $\left(-20{ }^{\circ} \mathrm{C}\right)$ on the same date of collection $(<2 \mathrm{~h}$ since euthanasia) until laboratory processing. The remaining individuals of non native species were euthanized according to the same procedure described above, while those of native fish species were kept in a tank with supplied oxygen (two battery operated aera tors with portable pump) until fully recovered before being released. All field procedures complied with animal use and care regulations of Europe and Spain (specific licences were granted for Scientific Field Re search in the River Ebro). Fish were collected by trained personnel (i.e. the holder of the licence, D. Almeida). Thus, no adverse effects were caused on the wildlife in the study habitats and all native fish fully re covered from the anaesthetic.

\subsection{PFAS analysis}

\subsubsection{Analysis of water samples}

Extraction and clean up were carried out by using the method described by Llorca et al. (2012b). Briefly, $500 \mathrm{ml}$ of seawater, $250 \mathrm{ml}$ of river water and wastewater effluents and $150 \mathrm{ml}$ of wastewater influents were spiked with $10 \mu \mathrm{l}$ of a mixture of surrogate internal standards at $100 \mathrm{ng} / \mathrm{ml}$. After $15 \mathrm{~min}$, a time period that is necessary in order to reach the equilibrium, the samples were filtered and extracted by solid phase extraction (SPE) with Oasis WAX cartridges $\left(30 \mathrm{~cm}^{3}, 60 \mathrm{mg}, 30 \mu \mathrm{m}\right.$; Waters Corporation, MA, USA) that were previously con ditioned with methanol and water. Cartridge elution was carried out with $4 \mathrm{ml}$ of $10 \% \mathrm{NH}_{4} \mathrm{OH}$ in methanol. The extracts were evaporated under a gentle $\mathrm{N}_{2}$ stream and reconstituted in 250 $\mu$ with a mixture of water and methanol (9:1). All the samples were processed in triplicates.

The extracts were analysed by ultra performance liquid chromatography coupled to a triple quadrupole mass spectrometer (UPLC QqQ MS/MS). Chromatographic separation was achieved with an Acquity UPLC BEH C18 analytical column $(2.1 \times 50 \mathrm{~mm}, 1.7 \mu \mathrm{m}$ particle size; Waters Corporation, USA) using the system Acquity UPLC H Class (Waters Corporation). A pre injection column PFASs isolator (Waters Corpo ration) was used, as well. Mobile phases consisted of $20 \mathrm{mM}$ ammonium acetate in water (solvent A) and $20 \mathrm{mM}$ ammonium acetate in methanol (solvent $\mathrm{B}$ ) and injection was delivered at a flow rate of $0.4 \mathrm{ml} / \mathrm{min}$. The elution programme was as follows: $20 \% \mathrm{~B}$ over a time period of $10 \mathrm{~s}$, then linear gradient to $80 \% \mathrm{~B}$ over another time period of $4 \mathrm{~min}$ and $50 \mathrm{~s}$, followed by a linear increase to 90\%B during $2 \mathrm{~min}$, followed by an isocratic hold at 90\%B for a time period of $2 \mathrm{~min}$ and $50 \mathrm{~s}$, and then an isocratic hold was implemented for $1 \mathrm{~min}$ more. At the minute 9:50, B was returned to $20 \%$ in $1 \mathrm{~min}$. The total run time for each injection was $11 \mathrm{~min}$ and the injection volume was $10 \mu \mathrm{l}$.

After separation, the detection was carried out using a triple quadrupole analyser Xevo TQ MS (Waters Co.) with an electrospray ionisation (ESI) source operating in negative conditions.

\subsubsection{Analysis of solid samples}

Sediment sample analyses were carried out by the method that was previously developed and validated by our group (Llorca et al., 2012b). For the extraction of sediment samples, $1 \mathrm{~g}$ dried sediment was spiked with $20 \mu \mathrm{l}$ of a mixture of internal standards $(100 \mathrm{ng} / \mathrm{ml})$ and left to reach equilibrium for $20 \mathrm{~min}$. After this period, $10 \mathrm{ml}$ of pure methanol was added, and the sediments were extracted by ultrasonic assisted ex traction (UAE) for $1 \mathrm{~h}$. The extracts were then centrifuged for $20 \mathrm{~min}$ at 
$4000 \mathrm{rpm}$ at $17{ }^{\circ} \mathrm{C}$. After centrifugation, $4 \mathrm{ml}$ of the supernatant was dried with a gentle stream of $\mathrm{N}_{2}$, reconstituted in $100 \mu$ of a mixture water:methanol (9:1) and directly injected in an on line clean up system. Extracts and the posterior analysis were performed in triplicates.

For the analysis of PFASs in fish, skin and muscle were processed separately, according to the validated procedure described by Llorca et al. (2012a). Briefly, $1 \mathrm{~g}$ of wet sample was spiked with $20 \mu \mathrm{l}$ of a mix ture of internal standards $(100 \mathrm{ng} / \mathrm{ml})$ and left at equilibrium for 20 min. The extraction procedure was based on alkaline extraction, mixing the sample with a solution of $10 \mathrm{ml}$ of methanol with $10 \mathrm{mM}$ sodium hy droxide and digesting for $2 \mathrm{~h}$ in an orbital shaker. After digestion, the mixture was centrifuged at $4000 \mathrm{rpm}$ and $17{ }^{\circ} \mathrm{C}$ for 20 $\mathrm{min}$. Then, $4 \mathrm{ml}$ of the supernatant was processed as described above for the analysis of PFASs in sediment samples (dried and reconstituted before on line clean up process). Due to the differences in weight and size of the se lected species, the smallest fish samples were processed and analysed as a pool of individuals, whereas the biggest fish samples were treated as individuals. Whenever possible, the guts were removed from the fish body and only muscle and skin tissues were analysed, but whenever this was impossible, the whole fish body was extracted and analysed.

Extracts of sediments and fish were purified in an on line clean up system (Thermo Fisher EQuan ${ }^{\mathrm{TM}}$ ) based on turbulent flow chromatogra phy (TFC). For the purification, two columns were used, Cyclone ( $50 \mathrm{~mm} \times 0.5 \mathrm{~mm}, 60 \mu \mathrm{m}$ particle size, $60 \AA$ pore size $)$ and C18 XL (50 mm $\times 0.5 \mathrm{~mm}, 60 \mu \mathrm{m}$ particle size, $60 \AA$ pore size), connected in tan dem. Loading and eluting solvents are summarised in Table S2. After pu rification, the extracts were directly pumped to the analytical column Hypersil GOLD PFP $(3 \times 50 \mathrm{~mm}, 3 \mu \mathrm{m}$ particle size; Thermo Fisher Scien tific). Sample injection volume was set at $20 \mu \mathrm{l}$. Detection was carried out using a triple quadrupole analyser TSQ Quantiva (Thermo Fischer Scientific) equipped with an electrospray ionisation (ESI) source oper ating in negative conditions.

\subsection{Quality assurance and quality control}

In order to rule out any system contamination, instrumental blanks made of methanol:water (1:9) were run every three sample injections, while different points of the calibration curve were analysed before, during and after samples in order to check sensibility drifts. For water analyses, procedural blanks were prepared in parallel to samples in order to discard any contamination step during sample treatment.

In Tables S3 and S4, the method limits of detection and quantification, and the recoveries for different matrices, respectively, are presented.

\subsection{Data analysis}

Statistical analyses were performed with $\mathrm{R}$ software. All the values that were below the method limit of quantification (mLOQ) were substituted with half the limit of quantification. Variables with $<10 \%$ of detections were removed from the dataset for statistical analyses. Correlation between variables in the different matrices was investigated using Spearman's rank order correlation. Differences among the sea sonal periods were studied through the non parametric Kruskal Wallis test. Reported values are means \pm SD. The significance level was set at $p$ value $(\alpha)<0.05$.

\section{Results and discussion}

In water samples, among the 13 selected PFASs, only 5 compounds were detected in all of the sampling campaigns (autumn 2015; winter and spring summer 2016), with perfluorocarboxylic acids (PFCAs) being the most abundant group. Table S5 summarises the main physicochemical parameters of water samples, while Table S6 provides a com parison between campaigns, along with summary statistics of the analysed PFASs. PFOA was the carboxylic acid detected at the highest frequency (67\% in autumn $2015,42 \%$, in winter and $76 \%$ in spring), followed by PFPeA (30\%, $17 \%$ and 66\%, respectively) and PFNA (22\%, $21 \%$ and $31 \%$, respectively). Among perfluorinated sulfonates, PFOS was the most abundant compound with frequencies of $22 \%$ in autumn, $4 \%$ in winter and $86 \%$ during spring. Additionally, PFOS was almost the unique sulfonate compound detected, with the exception of PFHxS, found only in one sample during the autumn period, and PFDS, detected only during the spring period. PFOSA was not detected in any of the analysed samples. PFOA and PFOS were the most commonly com pounds found in river water, which is in agreement with previous stud ies (Campo et al., 2015; Llorca et al., 2012a; Valsecchi et al., 2015). Though, it is worth to be noted that PFOS annual average concentrations $(0.52 \mathrm{ng} / \mathrm{l}$ in freshwater and $0.26 \mathrm{ng} / \mathrm{l}$ in seawater) were below the EQS set by EU Directive 2013/39/EU. Moreover, PFUdA, PFDA and PFDS were the only longer chain compound detected, at low frequencies. In detail, PFUdA was present in only two samples from the winter campaign, whereas PFDA and PFDS were recorded only in spring season. Lower distribution of longer chain compounds in water samples is not surpris ing, firstly because of their lower solubility, and secondly because of their current replacement in human production with shorter chain compounds, which have lower bioaccumulation potential (Onghena et al., 2012).

Table S7 reports concentrations of PFASs in surface waters of different published studies. Globally, the most abundant compound was once again PFOA, confirming the results showed in this work. Shorter chain compounds, especially PFHxA were also quite abundant, as in Yangtze River (China) or in Ebro River (Spain), confirming their high solubility and their increase in use and production in spite of the longer chain PFASs. Sulfonates, and PFOS above all, showed a similar span of values, comparable to PFOA (for comparison of range values, see Table S7).

In water samples we found that the concentrations of PFASs were minor during the winter period (Fig. 1), coinciding with a higher dilution after the rainy season, as it can be inferred from the mean flow rate of Ebro River, which was c.a. $160 \mathrm{~m}^{3} / \mathrm{s}$ during autumn and spring, and c.a. $450 \mathrm{~m}^{3} / \mathrm{s}$ in winter (Table S5). However, the concentrations can be considered fairly constant along the course of the year. As expect ed, the major concentrations were reported in wastewater, with PFPeA being the compound reaching the highest concentrations, with 2329, 2775 and $345 \mathrm{ng} / \mathrm{l}$ in autumn, winter and spring, respectively, in agree ment with its use as replacement compound (Wang et al., 2013). Never theless, effluents collected after the WWTPs showed a great efficiency in the removal of PFPeA from contaminated waters. In contrast, the two WWTPs revealed that they were inefficient in the removal of the other PFASs. For example, in the samples collected during autumn 2015, in spite of the significant removal of PFASs during the wastewater treat ment, the final effluents of both WWTPs, Amposta and Sant Carles de la Ràpita, still showed notable concentrations of PFOA. The influents of Amposta and Sant Carles were 6.8 and $8.7 \mathrm{ng} / \mathrm{l}$ of PFOA while the final effluents were 3.5 and $6.0 \mathrm{ng} / \mathrm{l}$ of PFOA, respectively, indicating that $>50 \%$ of this compound remains in the effluent. Higher concentrations of PFASs in effluents than in influents of WWTPs have already been re ported by different studies as a result of the incomplete degradation of their precursors (such as polyfluoroalkyl phosphates and fluorotelomer alcohols) during water treatment processes with activated sludges (Guo et al., 2010; Lee et al., 2010; Loos et al., 2013b; Wang et al., 2005). Detec tion of PFHpA only at the effluents of the Sant Carles de la Ràpita WWTP is a further evidence of other related PFASs (e.g. fluorotelomers) partial degradation into shorter chain PFASs. In river waters, the concentra tions were below $6 \mathrm{ng} / \mathrm{l}$ of PFOA as the most recalcitrant, followed by PFHxA and PFNA. It is noteworthy that the control site "before Amposta", located in the Ebro River far from the estuary area and select ed as reference site, reported a slight contamination by PFASs, especially for PFCAs. This fact suggests that contamination of the estuary environ ment is not only due to the different surrounding human activities, which may impact on water quality, but reflects a contamination which originates at a far distance from the estuary. As it can be 
Water samples

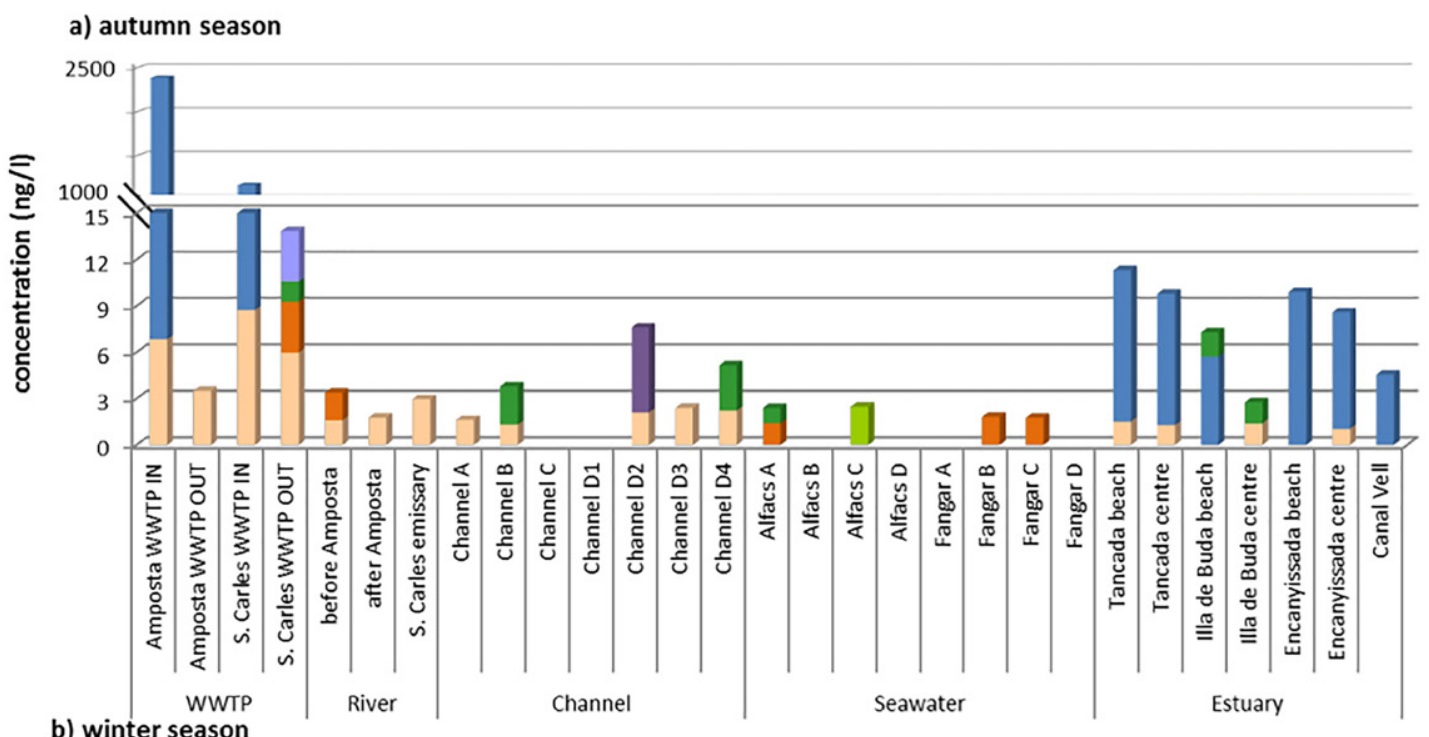

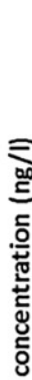
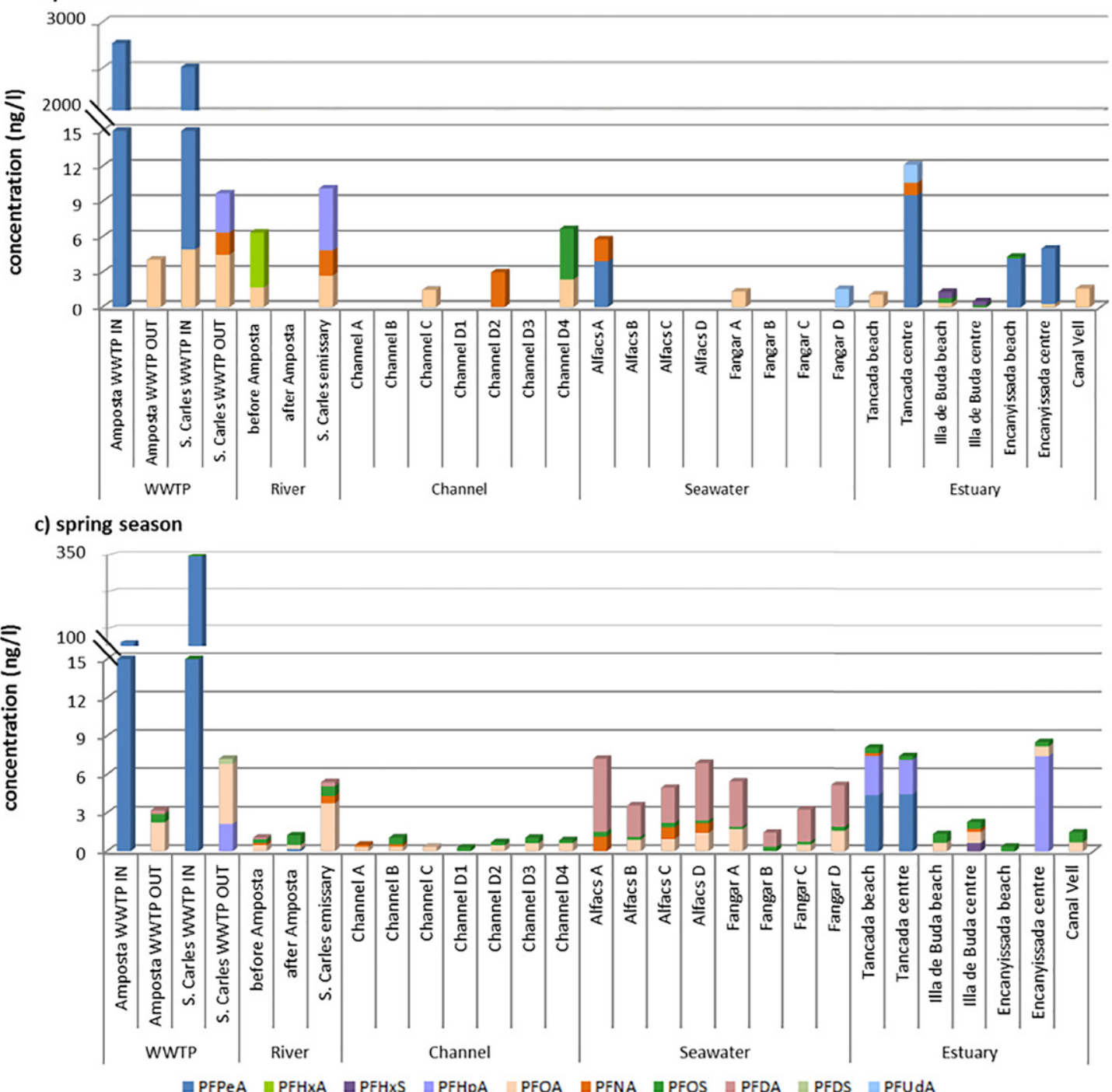

Fig. 1. PFAS concentrations (ng/l) detected in water samples during the autumn season (a), winter season (b) and spring-summer season (c). 
appreciated in Fig. 1, the final part of the Ebro Delta (La Tancada, L'Encanyissada and Illa de Buda) was more affected by PFASs contamination, since it collects all waters from the surrounding irrigation chan nels. Comparing river water and seawater concentration patterns over the year, it is noteworthy that samples taken during the winter period showed lower concentrations than those samples collected during the autumn and spring summer periods. Although PFOA still remained the most frequent compound among all PFASs, its frequency of detec tion decreased during the second sampling campaign, but was compa rable between the first and third sampling campaigns (52\% in autumn, 35\% in winter, 55\% in spring, excluding WWTPs data). In agreement with these data, the average concentrations for PFOA were 1.6, 0.97 and $0.87 \mathrm{ng} / \mathrm{l}$ in freshwaters (without WWTPs) for autumn, winter and spring, respectively (excluding WWTPs data). The dilution factor due to annual fluctuation of the Ebro River should be taken into account for freshwater samples: the lower PFAS concentrations detected in the wet winter season were due to the higher river flow rate of Ebro River (as explained before), while lower river flow rates lead to a higher concentration of contaminants in water during the dry season. In addition to the fluctuations of the Ebro River flow rates, the increment of popu lation during the summer autumn period, and specific weather condi tions during the different sampling campaigns (i.e. temperature and evaporation rates) may influence PFASs occurrence in the aquatic compartment.

In spite of that, no significant differences $(p>0.05)$ were found regarding the total PFAS concentrations over the year, stating their persis tence in the water compartment. In addition, the specific features of non polar compounds must be noted. For example, it is known that PFOS is partitioned into sediments (see next section) and that the con centrations detected in water are related to suspended organic material. In this case, the concentration of non polar compounds can be influ enced by heavy rain periods that redilute these compounds and incre ment their concentration in water, with a resulting constant trend of concentrations throughout the year.

The concentration data regarding sediment samples are summarised in Fig. 2 and Table S8. As in waters, for the first sampling campaign the most common compound was PFOA, detected in almost all analysed samples (96\% frequency), along with PFHxA and PFHpA, recorded in $41 \%$ and $36 \%$ of samples, respectively. Among sulfonates, PFOS was pre dominant, with a maximum of $22.6 \mathrm{ng} / \mathrm{g} \mathrm{dw}$ and mean value of $2.7 \pm 5.6 \mathrm{ng} / \mathrm{g} \mathrm{dw}$ in autumn. It is noteworthy that during the winter period the only PFASs detected were PFOA and PFOS, and they were at lower concentrations compared to autumn sampling (mean value in winter of $0.84 \pm 1.10 \mathrm{ng} / \mathrm{g} \mathrm{dw}$ for PFOA; $0.61 \pm 0.50 \mathrm{ng} / \mathrm{g} \mathrm{dw}$ for PFOS) and lower frequencies (25\% for PFOA, $15 \%$ for PFOS). PFDoA was also de tected in both sampling periods, but at a higher frequency in winter (15\%) than in autumn (5\%), even if at low concentrations (mean value $0.91 \pm 0.29 \mathrm{ng} / \mathrm{g} \mathrm{dw}$ ). Samples collected during the spring period did not show any concentration of PFASs above the mLOQ.

Globally, sediment mean concentrations found in this work were in agreement with those ones recorded in the upstream section of Ebro River recorded by Lorenzo et al. (2016) and with other rivers of the Spanish peninsula (Campo et al., 2016). Though, they were much higher than concentrations detected in Yangtze River sediments (Pan et al., 2014a, 2014b) and in Chinese river sediments (Pan et al., 2014a), due to different sources of introduction and different environmental charac teristics of rivers. For a better comparison of the ranges detected in those works, please refer to Table S7.

Fig. 2 reports the distribution of PFAS concentrations during autumn and winter periods. The most contaminated sites were the two lagoons of Illa de Buda and L'Encanyissada, along with Canal Vell, where PFOA and PFOS concentrations were accompanied by the detection of some of their replacement products in the autumn season (PFHxA, PFHpA, PFHxS, PFBS). Winter season displayed an evident decrease in PFASs de tection, especially for samples taken from the open sea, where no com pound was recorded; the estuarine environment showed a similar trend, with only some positive measurements in Illa de Buda and Canal Vell. Samples collected in the freshwater system, on the other hand, showed higher similarities between the two seasons. The Kruskal Wallis test that was run on the samples of the first and second campaigns confirmed the different biogeochemical features between the two sampling periods, showing statistically significant differences for the occurrence of PFHxA, PFHpA, PFOA and PFNA $(p<0.05)$, which are reported in Table S9. This seasonal pattern suggests that PFAS concentrations in sediments strongly depend not only on water sediment interactions, but also on the surrounding environmental conditions, such as temperature, precipitations and water currents that may occur consequently to the higher rainfall rates. In this context, the decrease in concentrations of PFASs in sediments could be due to a resuspension of sediments in coincidence with the rainy season, leading to an in crease of PFASs in the dissolved particulate matter and a correspondent decrease in sediments.

Only a few works focusing on PFAS seasonal trend in water and sed iment have been conducted so far. Pan et al. (2014a) found no substan tial variation of PFASs in sediments of Yangtze River in summer and winter seasons, even though the detected concentrations were very low ( $\sum$ PFASs range of $0.051 .44 \mathrm{ng} / \mathrm{g} \mathrm{dw}$ ), and most PFASs were not detected in the majority of the sampling sites. Pan et al. (2014b) in riv ers of the Pearl River Delta region (South China) also showed compara ble concentrations of PFASs in winter and summer, in contrast with the results obtained in this study. However, it should be highlighted that both studies were focused on river basins. The estuarine system of a delta environment is more complex since it is subjected to the influence of both inland waters and open seawaters. The anomalous behaviour of concentrations in sediments of Ebro delta could be explained by sedi ment resuspension that is produced consequently to heavy rainfalls during winter and spring, which leads initially to a depletion of the shorter chain compounds, less hydrophobic than the longer chain ones, as is actually registered for PFAS concentrations in winter season. Moreover, tidal events and strong water currents occurring during win ter period in the Mediterranean Sea could cause a mobilization of superficial sediments, resulting in the removal and transport of sediments towards far distant areas along the coastline, as an effect of coastal erosion.

Regarding the analysis of biota, the data which report PFASs accumulation in fish from Ebro River near the municipalities of Xerta and Tortosa are listed in Table S10, while the data of fishes that were collect ed in the Ebro Delta (estuarine and seawaters) are reported in Table S11. Notwithstanding the differences in sample preparation, PFOA was the most abundant compound, being detected both in the whole fish body and in muscle and skin tissues, and confirming its bioaccumulation po tential (Llorca, 2012). As could be expected, pool samples showed higher PFOA concentrations (from 94.2 to $330 \mathrm{ng} / \mathrm{g}$ ww) compared to samples for which only data on muscle and skin were available, since PFASs have been proved to bioaccumulate preferentially in liver and kidney, rather than in muscles or fat matter (Llorca, 2012). On the other hand, PFDA and PFOSA showed the highest frequencies of detec tion, being detected in all samples, with relatively high mean concentra tion for PFDA $(141 \pm 187 \mathrm{ng} / \mathrm{g}$ ww $)$ and lower values for PFOSA ( $7.4 \pm 6.0 \mathrm{ng} / \mathrm{g} \mathrm{ww})$. In particular, PFDA reached $459 \mathrm{ng} / \mathrm{g}$ ww in European cat fish (Silurus glanis), which is at the top of the aquatic food chain, and 454 and $455 \mathrm{ng} / \mathrm{g}$ ww in mullet fish (Liza sp.) and bleak (Alburnus alburnus), respectively, which both feed on small molluscs, insect lar vae, worms and small fishes. PFOS (range of values from $<$ mLOQ to $154 \mathrm{ng} / \mathrm{g} \mathrm{ww}$ ) and the short chain PFHxA (range $<$ mLOQ $122 \mathrm{ng} / \mathrm{g} \mathrm{ww}$ ) were also found at remarkable concentrations. Focusing, in more detail, on the individual contribution of PFASs in freshwater biota (Fig. 3), concentrations of whole body revealed a similar pattern in PFAS bio accumulation, both for pool samples (Fig. 3a) and for individual samples (Fig. 3b), showing the predominance of PFOA among all the PFASs. It is well known that the longer chain compounds exhibit more bioaccumulative potential than the shorter chain compounds. In this 


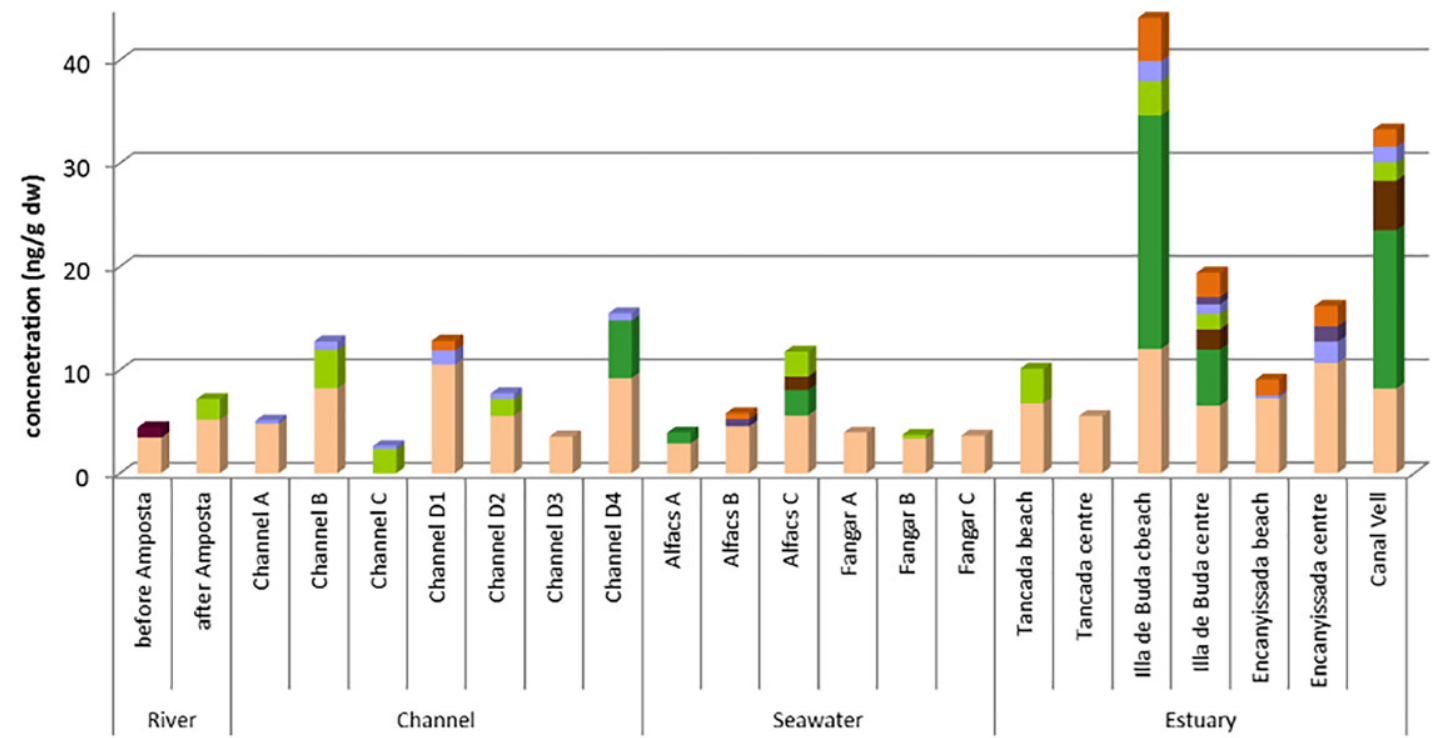

b) winter season

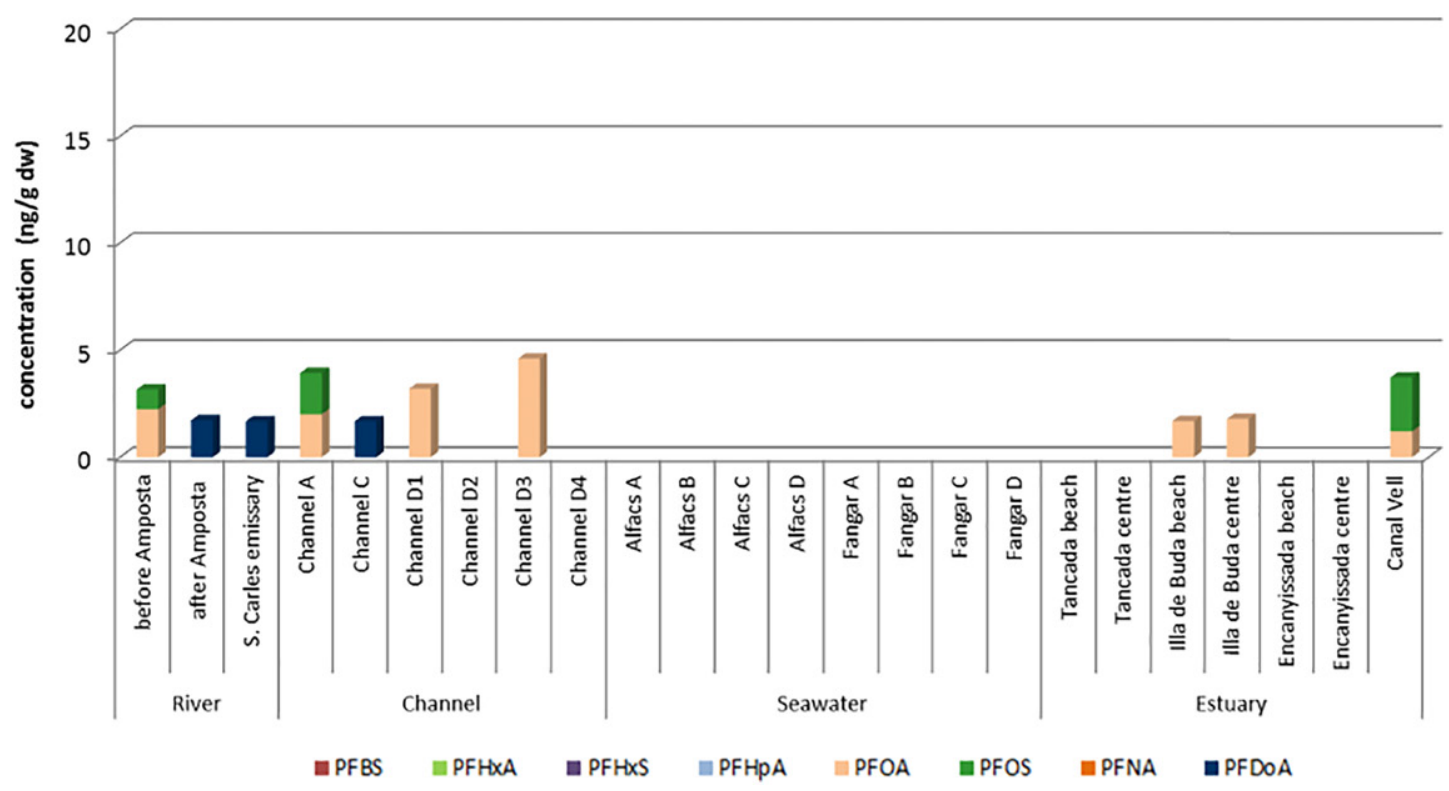

Fig. 2. PFAS concentrations (ng/g dw) detected in sediment samples during the autumn season (a) and the winter season (b).

study PFDA was the most frequently long chain detected compound, contributing to the total PFAS amount of $9 \%$ on average, and comparable to the 6 carbon chain PFHxA ( $5 \%$ of total contribution). This suggests that, due to their higher use and replacement of 8 chain PFASs, short chain compounds could lead over time to similar hazardous effects on organisms as those normally associated with long chain compounds. PFOSA was detected in species such as Cyprinus carpio and Silurus glanis, even though no concentrations above the mLOQ were registered in wa ters or sediments. These fishes are long lived species, reaching large sizes, and moreover, Silurus glanis is a common predator at the top of the aquatic food chain; PFOSA detection only in these species could be clear evidence of the biomagnification process throughout the trophic chain. In addition, detected concentrations of PFOSA can originate from amination of PFOS (Dimitrov et al., 2004) or from the metabolisation of the $N$ ethyl perfluorooctane sulfonamido ethanol (N Et FOSE) (Frömel Tobias, 2010). Lower detection of PFOA in muscle and skin tissue (Fig. 3c), in comparison to the concentration registered in the whole body (Fig. 3a and b), reinforce its preferential partition in liver, whereas PFDA showed a higher detection frequency, reaching almost $60 \%$ of PFAS contribution in fish muscle skin tissues.

PFASs accumulation in fish organisms has already been studied by several authors, although the high differences in fish preparation, as well as the wide variety of analysed species, make it difficult to compare the results. Nevertheless, a rough comparison of the results obtained in the study can be done with values taken from literature and reported in Table S7. As it can be seen, data regarding fish biota can be very different from one work to another, and are mostly dependent on the species se lected and their habits. However, as a general pattern displayed in the majority of works, PFOS shows to be the most bioaccumulative com pound, while among PFCAs, the longer chain compounds $(>\mathrm{C} 8)$ are the most abundant and the most frequently detected ones.

Data of freshwater biota were particularly compared to the results reported by Lorenzo et al. (2016) in the Ebro River, in order to compare the results obtained in different time periods but in the same river, even 


\section{Freshwater fishes}

a) pool samples (whole tissue)



c) individual samples (muscle and skin tissues) b) individual samples (whole tissue)

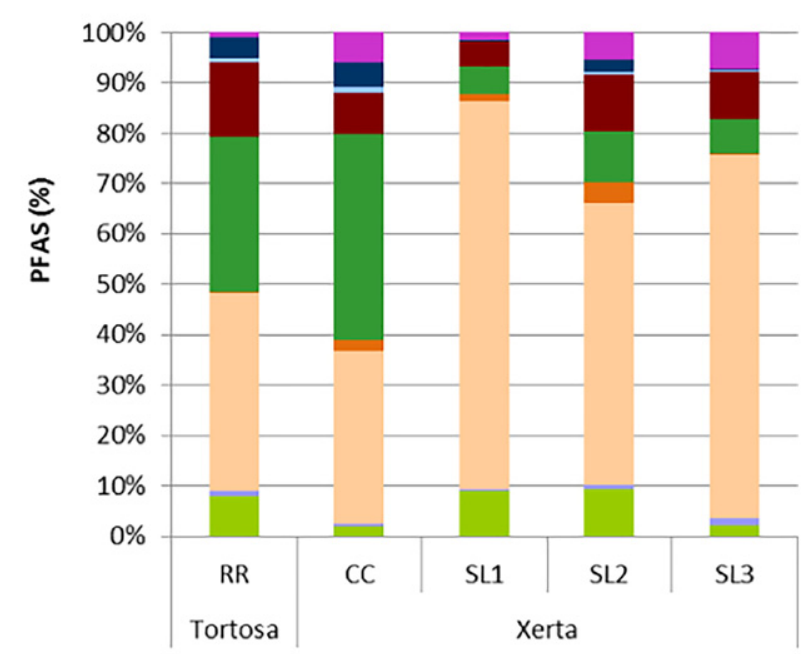

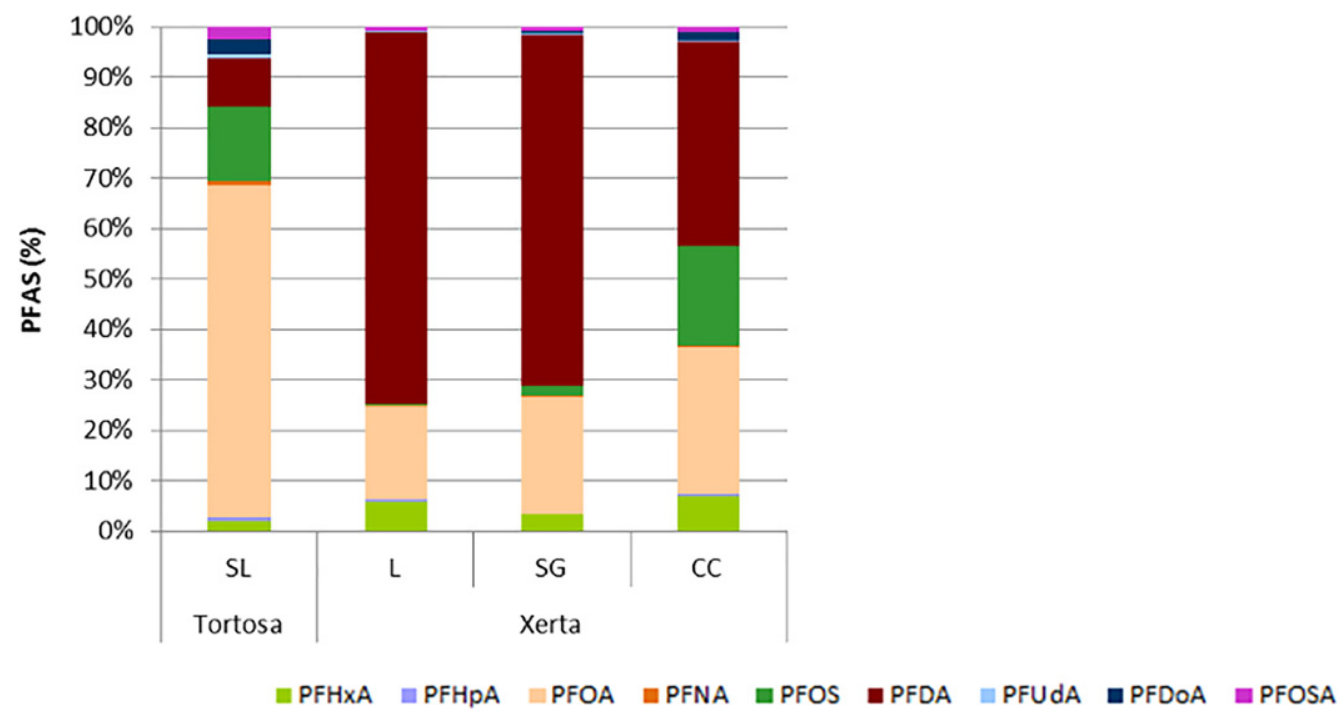

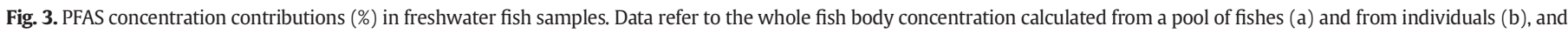

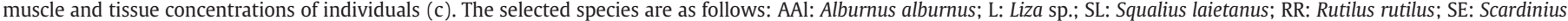
erythrophthalmus; CC: Cyprinus carpio; SG: Silurus glanis.

though the fishes that were analysed by the authors belong to the river upstream section, while fishes analysed in this work are closer to the Delta River mouth. Overall, both studies reported the occurrence of PFCAs such as PFOA and PFHxA as the main PFASs accumulated in biota. This is in contrast with the majority of other studies (Labadie and Chevreuil, 2011; Houde et al., 2011; Xu et al., 2014; Ye et al., 2008) that assessed perfluorinated sulfonates, and PFOS among all of them, as the most bioaccumulative of the perfluoroalkyl group. The major content of PFCAs in fish could be due to the higher occurrence of perfluorocarboxylic acids than sulfonates found in waters. However, concentrations of almost all PFASs detected in this study were much higher than those obtained by Lorenzo et al. (2016). Moreover, these very high values seemed not to be related to water data, which in turn showed much lower concentrations ( $\sum$ PFASs of Ebro River near Xerta: $3.4 \mathrm{ng} / \mathrm{l}$ in autumn, $6.4 \mathrm{ng} / \mathrm{l}$ in winter and 1.0 $\mathrm{ng} / \mathrm{l}$ in spring summer). Bioaccumulation is the result of long time interactions be tween organisms and the contaminated environment, and can be thus considered the evidence of water contamination events occurred in the past. Furthermore, fishes can move freely along the river and may have been affected by PFASs in different river transects far from the sampling area. Size and age of species, as well as gender, additionally in fluence the contaminants bioaccumulation and biotransformation pro cess (Houde et al., 2011). All these aspects can thus explain such high PFASs concentrations detected in riverine fishes.

For each of the fish species collected in Xerta, a PFAS experimental bioaccumulation factor was calculated according to the formula BAF $=C_{b} / C_{w}$, and expressed as $\mathrm{L} / \mathrm{kg}$. $C_{b}$ is the PFAS concentrations in fish and $C_{w}$ its concentration in water, considering a mean value of water concentrations detected in Xerta throughout the year. BAF values were calculated only for PFHxA, PFOA, PFNA and PFOS because detec tions in water above the $\mathrm{MLOQ}$ were only available for these compounds in at least two sampling campaigns. LogBAF values are reported in Table S12. Among the four variables, PFNA showed the low est logBAF values, while PFHxA, PFOA and PFOS showed comparable 
values (mean value of 4.2 for PFHxA, 5.1 for PFOA and 5.0 for PFOS), sug gesting a higher bioavailability and uptake of these compounds in com- parison to PFNA.

Contamination by PFASs was also found in fish collected from the es tuarine and coastal areas (Fig. 4). For these species, it was possible to separate skin from muscle, therefore, results for these two tissues are displayed separately. In this case, PFOS was the predominant compound, with the highest concentrations detected in Illa de Buda lagoon: the common carp (Cyprinus carpio, $14.5 \mathrm{ng} / \mathrm{g} \mathrm{ww}$ ) and the European eel (Anguilla anguilla, $21.6 \mathrm{ng} / \mathrm{g} \mathrm{ww}$ ). PFUdA and shorter chain PFCAs (PFNA, PFOA, PFHpA, PFHxA) were also detected, but at lower concen trations $(<5 \mathrm{ng} / \mathrm{g} \mathrm{ww})$. On the other hand, the flathead grey mullet (Mugil cephalus) and the largemouth bass (Micropterus salmoides) showed lower concentrations (max value of $4.2 \mathrm{ng} / \mathrm{g}$ ww for PFOS). Among the marine fishes that were collected in the open sea (Alfacs Bay and Fangar Bay), only the salema (Sarpa salpa) did not present con tamination by PFASs. This is consistent with its feed which is based on algae. Fishes taken at Alfacs Bay showed slightly higher concentrations of PFASs with respect to Fangar Bay, especially regarding muscle tissue. The fish species common torpedo (Torpedo torpedo) and bogue (Boops boops) were found to be very similar in their PFAS accumulation level, even though they are characterised by different behavioural habits (Torpedo torpedo is a benthic predator, while Boops boops is an omnivo rous semi pelagic organism). Anyway, the very low range $(<2 \mathrm{ng} / \mathrm{g} \mathrm{ww})$ at which PFAS concentrations were detected did not allow to distin guish any possible difference in the uptake of PFASs between the two species. No differences were found for PFAS distribution in muscle and skin tissues, except for PFHxA ( $p$ value of Kruskal Wallis test $=0.02$ ), as can be seen in the graphs, where PFHxA is preferentially distributed in fish skin, rather than in muscle. It is well known that PFASs tend to bind preferentially to protein and accumulate in liver and blood (Kannan et al., 2005); the higher concentrations found in the skin for PFHxA are thus not likely to be related to a bioaccumulation process of the organisms, but rather to skin contact with contaminated lagoonal sediments.

Overall, the estuarine and marine biota analysed in this study showed an accumulation of perfluoroalkyl substances that are not found in waters or sediments, such as the short chain PFHxA and PFHpA (see Figs. 1 and 2 for comparison). This is consistent with the fact that these compounds in waters and sediments are influenced by a high variability, due to the continuous changes of environmental con ditions (e.g. temperature, $\mathrm{pH}$, precipitation rates, water currents), while bioaccumulation through the aquatic food chain is the product of a lon ger time period exposure of organisms to contaminants. Seawater fishes showed lower concentrations compared to freshwater fishes, in con trast to what would be expected from water and sediments results, which highlighted a greater contamination of Illa de Buda lagoon, locat ed in the final stretch of the Ebro Delta, with lower salinity than seawa ter sampling points, but much higher salinity than freshwater zones (Table S5). PFAS biota concentrations that are higher in freshwater than in seawater ecosystems have already been reported, and a possible explanation can be related to the lower solubility, and thus lower bio availability, of PFAS in marine water (Zhao et al., 2011). It is noteworthy, however, that the majority of the species that were captured in the

\section{Seawater fishes}

a) Alfacs bay



b) Fangar bay

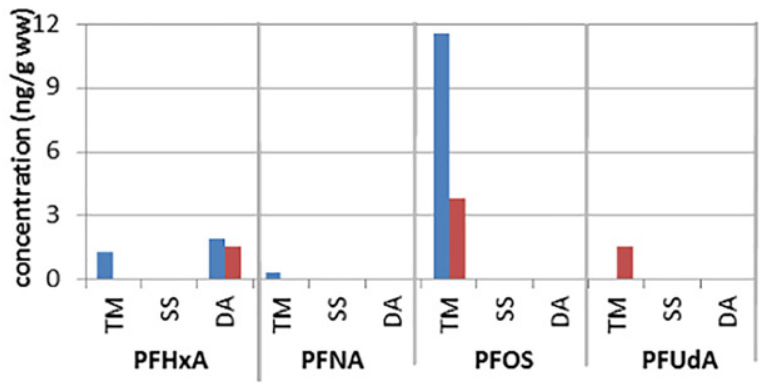

\section{c) Illa de buda lagoon}

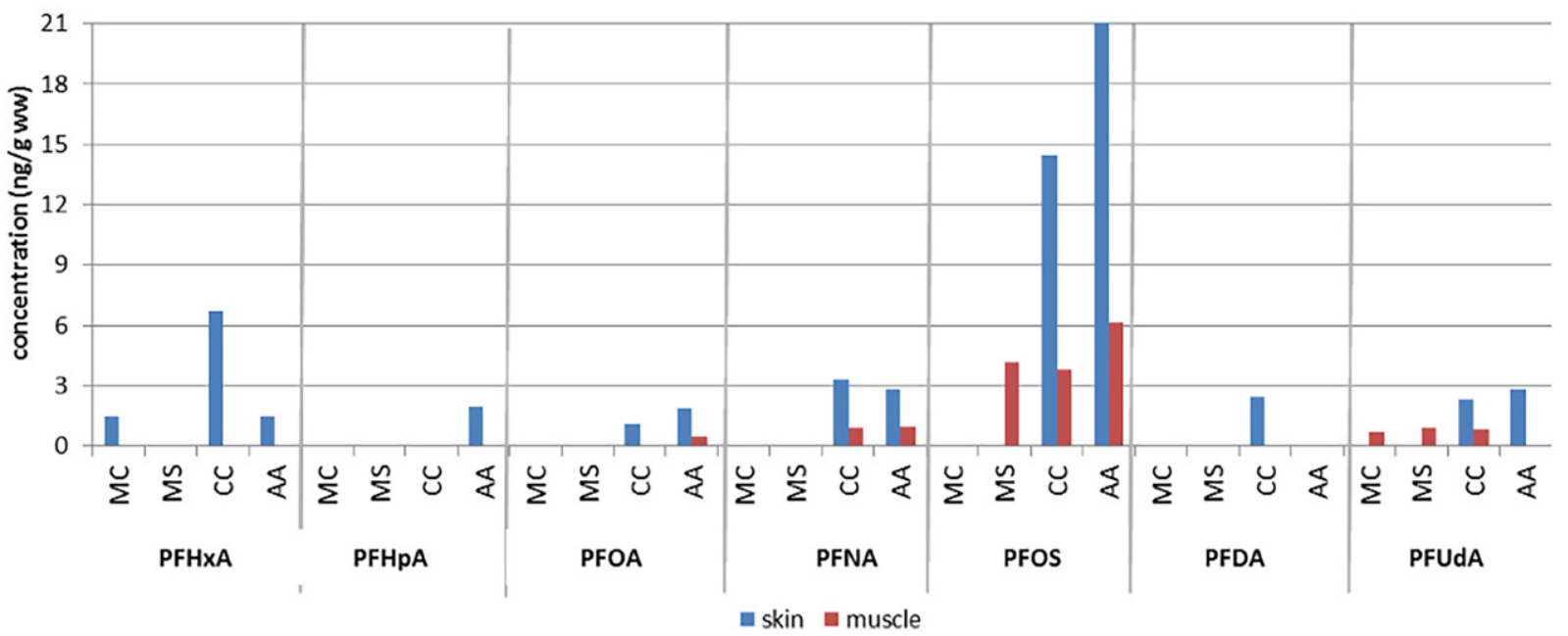

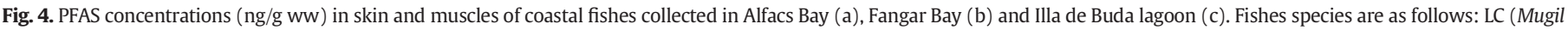

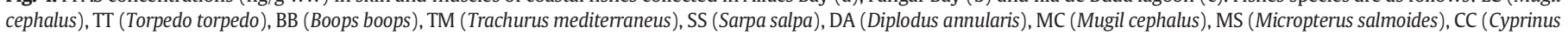
carpio), AA (Anguilla anguilla). 
estuarine area and in river were different. Among the common species that were captured in both environments, such as the common carp, those from Illa de Buda were younger. Caution should thus be exercised in comparing these results.

Although, in this study, the common carp (Cyprinus carpio) was the most affected species with respect to PFAS accumulation in tissues, both in river and estuarine environments. Bioaccumulation of contaminants is strictly species specific, being mostly dependent on the metabolism of the selected organism. The results of this study point out that the common carp is a good marker of PFAS contamination in biota, as it is also well known for the many POPs and metal pollutants. These results should be taken into consideration when addressing future research on PFAS bioaccumulation.

PFASs accumulation in fish is an issue of great concern, since it can be related to human exposure to PFASs through intake of contaminated fish. In this context, EU Directive 2013/39/EU set an Environmental Quality Standard (EQS) for PFOS in fish biota of $9.1 \mu \mathrm{g} /$ $\mathrm{kg}$, in order to safeguard ecosystem and human health; no EQS for the other PFASs have been set yet, as a consequence of the lack of information about their real toxicity levels. Concentrations detected in this study in the ed ible muscle tissue of seawater fishes were acceptable according to the EU Directive; on the contrary, almost all freshwater fishes exceeded the EU threshold for PFOS (range $<\mathrm{mLOQ}$ $154 \mu \mathrm{g} / \mathrm{kg} \mathrm{dw}$; mean value $49.7 \pm 50.7 \mu \mathrm{g} / \mathrm{kg} \mathrm{dw}$ ), thus revealing a very anomalous situation in Ebro River. To conclude, PFASs accumulation in freshwater fishes should thus be better analysed, considering that PFOA and PFDA showed even higher concentrations than PFOS, in order to understand if PFAS levels detected in fish of Ebro River can pose a risk for human beings or the ecosystem.

\section{Conclusions}

This study focused on the occurrence and biogeochemical features of PFASs in waters, sediments and fishes of the Ebro Delta region (Catalonia, Spain). Sampling campaigns in different time periods were carried out in order to investigate seasonal trends of PFASs. The study revealed a difference in the sampling campaigns that is likely due to the different environmental conditions, with the main influencing factors being temperature and rainfall regimes. PFOA was confirmed to be the predominant compound among all the perfluoroalkyl substances, both in water and in sediment. With respect to waters, PFPeA was the most abundant compound, reaching very high concentrations, especially in the WWTPs, as a consequence of its widespread use as an alternative to PFOA and PFOS. Concerning sediments, PFOS was found to be the most abundant perfluorinated compound, being detected at higher concentrations than those found in waters, and revealing its preferential behaviour to be adsorbed on sediment particles rather than staying in a water dissolved phase. Sediments registered a very different pattern of PFASs than did water, consisting of a progressive decrease in the occurrence of PFASs throughout the year. This decrease re flects a very high influence of the environmental conditions on PFAS distribution in sediments and suggests water sediment partitioning is happening over a long term time scale. Seawater fishes showed PFAS concentrations higher in their skin than in their muscle tissues; PFOS was once again the most abundant and the most detected compound. Results on waters, sediments and biota confirmed Illa de Buda to be the most contaminated site of the Ebro Delta. On the other hand, freshwater fishes showed very high concentrations of both sulfonates and carboxylic acids, in contrast with those ones registered for seawater fishes. Such high differences in concentrations could be due to a different uptake mechanism between freshwater and seawater fishes and to the different behavioural habitats of the two fish types.

\section{Acknowledgements}

This work was supported by the Spanish Ministry of Economy and Competitiveness through the project Integra Coast (CGL 201456530 C4 $1 \mathrm{R}$ ), and by the Generalitat de Catalunya (Consolidated Research Groups "2014 SGR 418 Water and Soil Quality Unit"). ML acknowledges her Juan de la Cierva Incorporación research fellowship (JCI 2014 21736). DA held a postdoctoral fellowship from the 'Beatriu de Pinós' programme, funded by the Generalitat of Catalunya and the Marie Curie COFUND through the University of Girona.

\section{Appendix A. Supplementary data}

Supplementary data to this article can be found online at http://dx. doi.org/10.1016/j.scitotenv.2017.07.025.

\section{References}

Ahrens, L., 2011. Polyfluoroalkyl compounds in the aquatic environment: a review of their occurrence and fate. J. Environ. Monit. 13, 20-31.

Ahrens, L., Felizeter, S., Sturm, R., Xie, Z., Ebinghaus, R., 2009. Polyfluorinated compounds in waste water treatment plant effluents and surface waters along the River Elbe, Germany. Mar. Pollut. Bull. 58, 1326-1333.

Ahrens, L., Yeung, L.W., Taniyasu, S., Lam, P.K., Yamashita, N., 2011. Partitioning of perfluorooctanoate (PFOA), perfluorooctane sulfonate (PFOS) and perfluorooctane sulfonamide (PFOSA) between water and sediment. Chemosphere 85, 731-737.

Arvaniti, O.S., Stasinakis, A.S., 2015. Review on the occurrence, fate and removal of perfluorinated compounds during wastewater treatment. Sci. Total Environ. 524 81-92.

Boulanger, B., Vargo, J.D., Schnoor, J.L., Hornbuckle, K.C., 2005. Evaluation of perfluorooctane surfactants in a wastewater treatment system and in a commercial surface protection product. Environ. Sci. Technol. 39, 5524-5530.

Campo, J., Pérez, F., Masiá, A., Picó, Y., la Farré, M., Barceló, D., 2015. Perfluoroalkyl substance contamination of the Llobregat River ecosystem (Mediterranean area, NE

Spain). Sci. Total Environ. 503, 48-57.

Campo, J., Lorenzo, M., Pérez, F., Picó, Y., Farré, M., Barceló, D., 2016. Analysis of the presence of perfluoroalkyl substances in water, sediment and biota of the Jucar River (E Spain). Sources, partitioning and relationships with water physical characteristics. Environ. Res. 147, 503-512.

Cardoch, L., Day, J.W., Ibàñez, C., 2002. Net primary productivity as an indicator of sustainability in the Ebro and Mississippi deltas. Ecol. Appl. 12, 1044-1055.

Dimitrov, S., Kamenska, V., Walker, J., Windle, W., Purdy, R., Lewis, M., et al., 2004. Predicting the biodegradation products of perfluorinated chemicals using CATABOL. QSAR in Environmental Research]->SAR QSAR Environ. Res. 15, 69-82.

EU Commission Directive 2013/39/EU of the European Parliament and of the Council

of 12 August 2013 amending Directives 2000/60/EC and 2008/105/EC as regards prior-ity substances in the field of water policy. L. 226/1, Official Journal of the European Union, 2013.

Frömel Tobias, K.T.P., 2010. Biodegradation of fluorinated alkyl substances. In: Pd, Voogt (Ed.)Reviews of Environmental Contamination and Toxicology Perfluorinatedalkylated Substances vol. 208. Springer, New York Dordrecht Heidelberg London, p. 232.

Gao, Y., Fu, J., Meng, M., Wang, Y., Chen, B., Jiang, G., 2015. Spatial distribution and fate of perfluoroalkyl substances in sediments from the Pearl River Estuary, South China.

Mar. Pollut. Bull. 96, 226-234.

Guo, R., Sim, W.-J., Lee, E.-S., Lee, J.-H., Oh, J.-E., 2010. Evaluation of the fate of perfluoroalkyl compounds in wastewater treatment plants. Water Res. 44, 34763486.

Houde, M., De Silva, A.O., Muir, D.C.G., Letcher, R.J., 2011. Monitoring of perfluorinated compounds in aquatic biota: an updated review. Environ. Sci. Technol. 45, 7962-7973.

Houtz, E.F., Higgins, C.P., Field, J.A., Sedlak, D.L., 2013. Persistence of perfluoroalkyl acid precursors in AFFF-impacted groundwater and soil. Environ. Sci. Technol. 47, 8187-8195.

Jiang, J.-J., Lee, C.-L., Fang, M.-D., 2014. Emerging organic contaminants in coastal waters: anthropogenic impact, environmental release and ecological risk. Mar. Pollut. Bull. 85 ,

391-399.

Kannan, K., Tao, L., Sinclair, E., Pastva, S.D., Jude, D.J., Giesy, J.P., 2005. Perfluorinated compounds in aquatic organisms at various trophic levels in a Great Lakes food chain. Arch. Environ. Contam. Toxicol. 48, 559-566.

Labadie, P., Chevreuil, M., 2011. Partitioning behaviour of perfluorinated alkyl contaminants between water, sediment and fish in the Orge River (nearby Paris, France). Environ. Pollut 159, 391-397.

Lau, C., Anitole, K., Hodes, C., Lai, D., Pfahles-Hutchens, A., Seed, J., 2007. Perfluoroalkyl acids: a review of monitoring and toxicological findings. Toxicol. Sci. 99, 366-394.

Lee, H., D'eon, J., Mabury, S.A., 2010. Biodegradation of polyfluoroalkyl phosphates as a source of perfluorinated acids to the environment. Environ. Sci. Technol. 44, 33053310 .

Llorca, M., 2012. Analysis of Perfluoroalkyl Substances in Food and Evironmental Matrices. Analytical Chemistry. Dr. Universitat de Barcelona, Barcelona. 
Llorca, M., Farré, M., Tavano, M.S., Alonso, B., Koremblit, G., Barceló, D., 2012a. Fate of a broad spectrum of perfluorinated compounds in soils and biota from Tierra del

Fuego and Antarctica. Environ. Pollut. 163, 158-166.

Llorca, M., Farré, M., Picó, Y., Müller, J., Knepper, T.P., Barceló, D., 2012b. Analysis of perfluoroalkyl substances in waters from Germany and Spain. Sci. Total Environ. 431, 139-150.

Lloret, J., Palomera, I., Salat, J., Solé, I., 2004. Impact of freshwater input and wind on landings of anchovy (Engraulis encrasicolus) and sardine (Sardina pilchardus) in shelf wa-ters surrounding the Ebre (Ebro) River delta (north-western Mediterranean). Fish. Oceanogr. 13, 102-110.

Loos, R., Tavazzi, S., Paracchini, B., Canuti, E., Weissteiner, C., 2013a. Analysis of polar organic contaminants in surface water of the northern Adriatic Sea by solid-phase ex-traction followed by ultrahigh-pressure liquid chromatography-QTRAP® MS using a hybrid triple-quadrupole linear ion trap instrument. Anal. Bioanal. Chem. 405, 5875-5885.

Loos, R., Carvalho, R., António, D.C., Comero, S., Locoro, G., Tavazzi, S., et al., 2013b. EUwide monitoring survey on emerging polar organic contaminants in wastewater

treatment plant effluents. Water Res. 47, 6475-6487.

Lorenzo, M., Campo, J., Farré, M., Pérez, F., Picó, Y., Barceló, D., 2016. Perfluoroalkyl substances in the Ebro and Guadalquivir river basins (Spain). Sci. Total Environ. 540, 191-199.

Munoz, G., Giraudel, J.-L., Botta, F., Lestremau, F., Dévier, M.-H., Budzinski, H., et al., 2015. Spatial distribution and partitioning behavior of selected poly-and perfluoroalkyl substances in freshwater ecosystems: a French nationwide survey. Sci. Total Environ. 517, 48-56.

Naile, J.E., Khim, J.S., Wang, T., Chen, C., Luo, W., Kwon, B.-O., et al., 2010. Perfluorinated compounds in water, sediment, soil and biota from estuarine and coastal areas of

Korea. Environ. Pollut. 158, 1237-1244.

Onghena, M., Moliner-Martinez, Y., Picó, Y., Campíns-Falcó, P., Barceló, D., 2012. Analysis of 18 perfluorinated compounds in river waters: comparison of high performance liq-uid chromatography-tandem mass spectrometry, ultra-high-performance liquid chromatography-tandem mass spectrometry and capillary liquid chromatography-mass spectrometry. J. Chromatogr. A 1244, 88-97.

Pan, C.-G., Ying, G.-G., Zhao, J.-L., Liu, Y.-S., Jiang, Y.-X., Zhang, Q.-Q., 2014a. Spatiotempora distribution and mass loadings of perfluoroalkyl substances in the Yangtze River of China. Sci. Total Environ. 493, 580-587.

Pan, C.-G., Ying, G.-G., Liu, Y.-S., Zhang, Q.-Q., Chen, Z.-F., Peng, F.-J., Huang, G.-Y., 2014b. Contamination profiles of perfluoroalkyl substances in five typical rivers of the Pearl River Delta region, South China. Chemosphere 114, 16-25.

Pérez, F., Llorca, M., Köck-Schulmeyer, M., Škrbić, B., Oliveira, L.S., da Boit, Martinello K., et al., 2014. Assessment of perfluoroalkyl substances in food items at global scale. Environ. Res. 135, 181-189.

Pistocchi, A., Loos, R., 2009. A map of European emissions and concentrations of PFOS and PFOA. Environ. Sci. Technol. 43, 9237-9244.
Prevedouros, K., Cousins, I.T., Buck, R.C., Korzeniowski, S.H., 2006. Sources, fate and transport of perfluorocarboxylates. Environ. Sci. Technol. 40, 32-44.

Renzi, M., Guerranti, C., Giovani, A., Perra, G., Focardi, S.E., 2013. Perfluorinated compounds: levels, trophic web enrichments and human dietary intakes in transitional water ecosystems. Mar. Pollut. Bull. 76, 146-157.

Schultz, M.M., Higgins, C.P., Huset, C.A., Luthy, R.G., Barofsky, D.F., Field, J.A., 2006. Fluorochemical mass flows in a municipal wastewater treatment facility. Environ. Sci. Technol. 40, 7350-7357.

Schwanz, T.G., Llorca, M., Farré, M., Barceló, D., 2016. Perfluoroalkyl substances assessment in drinking waters from Brazil, France and Spain. Sci. Total Environ. 539,

143-152.

United States Environmental Protection Agency (US EPA), 2016. Drinking Water Health Advisory for Perfluorooctanoic Acid (PFOA) 822-R-16-005.

Valsecchi, S., Rusconi, M., Mazzoni, M., Viviano, G., Pagnotta, R., Zaghi, C., et al., 2015. Occurrence and sources of perfluoroalkyl acids in Italian river basins. Chemosphere 129, 126-134.

Wang, N., Szostek, B., Buck, R.C., Folsom, P.W., Sulecki, L.M., Capka, V., et al., 2005. Fluorotelomer alcohol biodegradation direct evidence that perfluorinated carbon chains breakdown. Environ. Sci. Technol. 39, 7516-7528.

Wang, Z., Cousins, I.T., Scheringer, M., Hungerbühler, K., 2013. Fluorinated alternatives to long-chain perfluoroalkyl carboxylic acids (PFCAs), perfluoroalkane sulfonic acids (PFSAs) and their potential precursors. Environ. Int. 60, 242-248.

Water Framework Directive: Proposal for a Directive of the European Parliament and

of the Council amending Directives 200/60/EC and 2008/150/EC as regards priority sub-stances in the field of water policy 2012.

Xu, J., Guo, C.-S., Zhang, Y., Meng, W., 2014. Bioaccumulation and trophic transfer of perfluorinated compounds in a eutrophic freshwater food web. Environ. Pollut.

$184,254-261$.

Ye, X., Strynar, M.J., Nakayama, S.F., Varns, J., Helfant, L., Lazorchak, J., et al., 2008. Perfluorinated compounds in whole fish homogenates from the Ohio, Missouri, and Upper Mississippi Rivers, USA. Environ. Pollut. 156, 1227-1232.

Zareitalabad, P., Siemens, J., Hamer, M., Amelung, W., 2013. Perfluorooctanoic acid (PFOA) and perfluorooctanesulfonic acid (PFOS) in surface waters, sediments, soils and wastewater-a review on concentrations and distribution coefficients. Chemosphere 91, 725-732.

Zhang, Y., Beesoon, S., Zhu, L., Martin, J.W., 2013. Biomonitoring of perfluoroalkyl acids in human urine and estimates of biological half-life. Environ. Sci. Technol. 47,

10619-10627.

Zhao, Y.G., Wan, H.T., Law, A.Y., Wei, X., Huang, Y.Q., Giesy, J.P., et al., 2011. Risk assessment for human consumption of perfluorinated compound-contaminated freshwater and marine fish from Hong Kong and Xiamen. Chemosphere 85, 277283. 